\title{
Effect of High-Temperature Heat Treatment on the Properties of Hardperm in the Ni-Fe-Ta System*
}

\author{
By Hakaru Masumoto**, Yûetsu Murakami** and Masakatsu Hinai**
}

\begin{abstract}
Considerable improvements of the magnetic properties of $\mathrm{Ni}-\mathrm{Fe}-\mathrm{Ta}$ alloys having a range of composition from 70.03 to $77.41 \% \mathrm{Ni}, 9.50$ to $15.96 \% \mathrm{Fe}$, and 9.57 to $17.80 \%$ Ta have been effected by heating in hydrogen atmosphere at high temperatures of 1050 to $1350^{\circ} \mathrm{C}$, followed by cooling at rates from 100 to $8100^{\circ} \mathrm{C} / \mathrm{hr}$. The highest value of 75000 in initial permeability and of 650000 in maximum permeability can be obtained with a composition of $73.00 \% \mathrm{Ni}, 11.60 \% \mathrm{Fe}$, and $15.40 \%$ Ta by cooling at the rate of $800^{\circ} \mathrm{C} / \mathrm{hr}$ after heating at $1250^{\circ} \mathrm{C}$ for $30 \mathrm{~min}$ and $3 \mathrm{hr}$, respectively. The alloy subjected to the latter heat treatment exhibits the electrical resistivity of $70.1 \mu \Omega-\mathrm{cm}$ and the Vickers hardness 211. The high permeability of the Ni-Fe-Ta alloys is largely due to the effective contributions of high-temperature heat treatment in hydrogen atmosphere to the homogeneity of the alloys, removal of impurities and grain growth, associated with the low value of magnetostriction caused by the atomic arrangement in the ordered state.
\end{abstract}

(Received June 29, 1974)

\section{Introduction}

In a previous paper ${ }^{(1)}$ it has been established that Ni-Fe-Ta alloys containing 3.20 23.90\% Ta exhibit a high permeability when melted in vacuum, heated in hydrogen atmosphere at $1150^{\circ} \mathrm{C}$ for $3 \mathrm{hr}$, and cooled at an optimum rate from a temperature above their order-disorder transformation points. In general, however, the magnetic properties of high permeability alloys depend strongly on composition and also heat treatment. The object of the present study is to clarify the magnetic properties of these alloys when subjected to homogenizing treatments in hydrogen atmosphere at different temperatures.

\section{Experimental}

The specimens used were 33 alloys having a range of composition from 70.03 to $77.41 \%$ $\mathrm{Ni}, 9.50$ to $15.96 \% \mathrm{Fe}$, and 9.57 to $17.80 \% \mathrm{Ta}$, since they have very high permeabilities ${ }^{(1)}$.

* This paper was presented at the 1973 Autumn Meeting of the Japan Institute of Metals. Reported originally in Japanese in J. Japan Inst. Metals, 38 (1974), 925; The 73 rd report from the Research Institute of Electric and Magnetic Alloys.

** The Research Institute of Electric and Magnetic Alloys, 107, Higashi 8-bancho, Sendai 980, Japan.

Trans. JIM
The numbering system of alloys follows that in the preceding paper. The ingots of the alloys prepared in the same manner as outlined previously $^{(1)}$ were first reduced to a final thickness of $0.3 \mathrm{~mm}$ by forging and subsequent hot and cold rolling, from which ring-shaped plates were made by stamping. The ring-shaped plates were heated at $1050 \sim 1350^{\circ} \mathrm{C}$ for $30 \mathrm{~min}$ to $25 \mathrm{hr}$ under a hydrogen atmosphere with a dew point of $-70^{\circ} \mathrm{C}$. After the heat treatment, the plate specimens were cooled down to room temperature at rates from 8100 to $100^{\circ} \mathrm{C} / \mathrm{hr}$ from a temperature above their order-disorder transformation points. The magnetic properties of the specimens were measured by means of a ballistic galvanometer and a recording fluxmeter; the magnetic transformation points with the aid of a magnetic balance; the magnetostriction by the optical roller method; the electrical resistivities by the potentiometric method; and the hardness values by means of a microVickers hardness tester.

\section{Results and Discussion}

The experimental data are graphically illustrated in Figs. $1 \sim 7$ and tabulated in Table 1. Figures 1 and 2 illustrate the statistically drawn equi-value curves of the highest values of initial and maximum permeabilities at $20^{\circ} \mathrm{C}$ against composition for each of $\mathrm{Ni}-\mathrm{Fe}-\mathrm{Ta}$ 


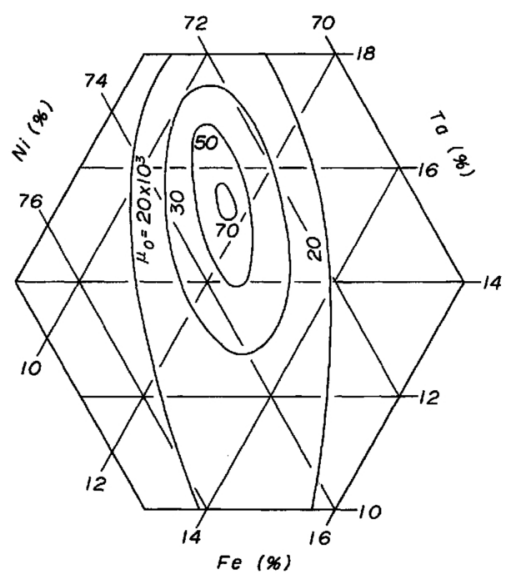

Fig. 1 Highest initial permeability $\mu_{0}$ in each of $\mathrm{Ni}-\mathrm{Fe}-\mathrm{Ta}$ alloys cooled at various rates from a temperature above order-disorder transformation point after heating at several high temperatures.

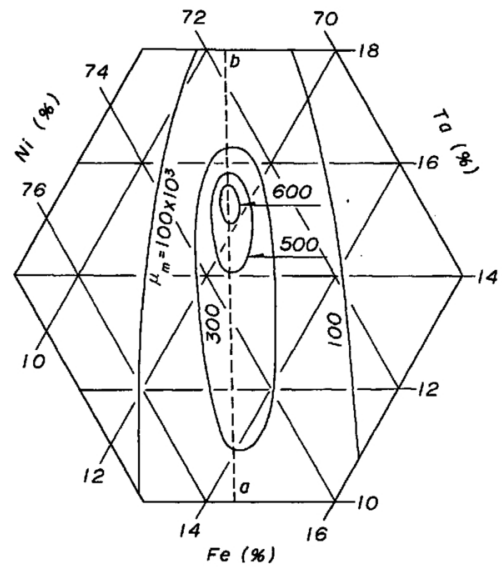

Fig. 2 Highest maximum permeability $\mu_{m}$ of the same alloys as in Fig. 1.

alloys which were heated at $1050 \sim 1350^{\circ} \mathrm{C}$ for various lengths of time and cooled at different rates from a temperature above their orderdisorder transformation points. Inspection of the figures shows that with increasing Ta concentration, the initial permeability $\mu_{o}$ and the maximum permeability $\mu_{m}$ increase until maxima are reached at about $15 \%$ and then the values are gradually reduced. The highest value of 75000 in $\mu_{o}$ and of 650000 in $\mu_{m}$ has been obtained with alloy No. 40 of $73.00 \mathrm{Ni}, 11.60 \%$ $\mathrm{Fe}$ and $15.40 \% \mathrm{Ta}$ by cooling at the rate of $800^{\circ} \mathrm{C} / \mathrm{hr}$ after heating in hydrogen atmosphere at $1250^{\circ} \mathrm{C}$ for $30 \mathrm{~min}$ and $3 \mathrm{hr}$, respectively. These values are fairly larger than those of

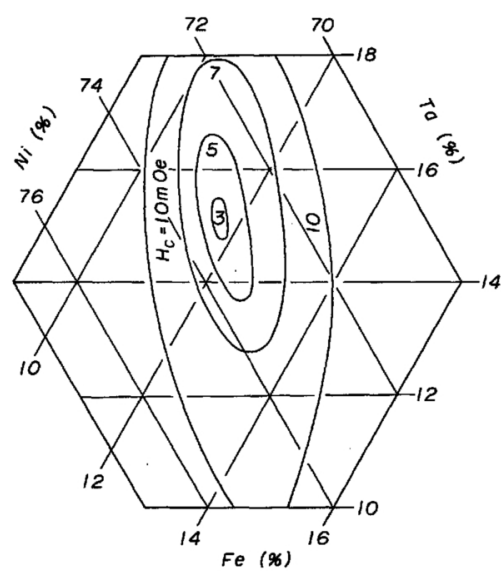

Fig. 3 Coercive force $H_{c}$ in Ni-Fe-Ta alloys heattreated to develop the highest maximum permeability.

57300 in $\mu_{o}$ and 428000 in $\mu_{m}$ for alloy No. 34 subjected to heating at $1150^{\circ} \mathrm{C}$ for $3 \mathrm{hr}$ under a hydrogen atmosphere. It will be noted that improvements in $\mu_{o}$ and $\mu_{m}$ are effected by high-temperature heat treatment under the hydrogen atmosphere.

Figure 3 shows the equi-value curves of composition vs coercive force $H_{c}$ (maximum magnetic induction: $5 \mathrm{kG}$ ), where the $H_{c}$ was obtained by the heat treatment by which the highest value of $\mu_{m}$ appeared in each of the alloys. With increasing Ta concentration, $H_{c}$ decreases until a minimum is reached at about $15 \%$; then the value increases rapidly. The lowest $H_{c}$ value of $2.9 \mathrm{mOe}$ was shown by alloy No. 40 subjected to cooling at the rate of $800^{\circ} \mathrm{C} / \mathrm{hr}$ after heating at $1250^{\circ} \mathrm{C}$ for $3 \mathrm{hr}$. This value is much smaller than the lowest $H_{c}$ of $5.2 \mathrm{mOe}$ obtained in the previous paper.

Magnetic properties, electrical resistivity and hardness for the representative alloys showing specially high permeability are listed with annealing condition and cooling rate in Table 1. In the table $\mu_{1}$ is the permeability in a field of $1 \mathrm{mOe} ; W_{h}$ and $B_{r}$ are the hysteresis loss and the residual magnetic induction against a maximum magnetic induction of $5 \mathrm{kG}$, respectively; $4 \pi I$ and $\lambda$ are the magnetic induction and the magnetostriction constant in an effective field of $1 \mathrm{kOe}$, respectively; $\rho$ is the electrical resistivity; $T_{c}$ is the magnetic transformation point; and $\mathrm{Hv}$ is the Vickers hardness 
Table 1 Magnetic properties, electrical resistivity and Vickers hardness of some high permeability $\mathrm{Ni}-\mathrm{Fe}-\mathrm{Ta}$ alloys.

\begin{tabular}{|c|c|c|c|c|c|c|c|c|c|c|c|c|c|c|c|c|}
\hline \multirow{3}{*}{$\begin{array}{l}\text { Alloy } \\
\text { No. }\end{array}$} & \multicolumn{2}{|c|}{$\begin{array}{c}\text { Composition } \\
(\mathrm{wt} \%)\end{array}$} & \multicolumn{2}{|c|}{ Heating } & \multirow{3}{*}{$\begin{array}{l}\text { Cool- } \\
\text { ing } \\
\text { rate } \\
\text { ( }{ }^{\circ} \mathrm{C} / \\
\mathrm{hr})\end{array}$} & \multirow{3}{*}{$\frac{\mu_{0}}{(}$} & \multirow{3}{*}{\multicolumn{2}{|c|}{$\frac{0}{\left(\times 10^{3}\right)}$}} & \multirow{2}{*}{$\begin{array}{c}W_{h} \\
(\mathrm{erg} / \\
\mathrm{cm}^{3} / \\
\text { cycle) }\end{array}$} & \multirow{2}{*}{$\begin{array}{c}B_{r} \\
(\mathrm{kG})\end{array}$} & \multirow{2}{*}{$\underset{(\mathrm{mOe})}{H_{c}}$} & \multirow{2}{*}{$\begin{array}{c}4 \pi I \\
(\mathrm{kG})\end{array}$} & \multirow{2}{*}{$\begin{array}{l}\lambda \\
\left.\times 10^{-6}\right)\end{array}$} & \multirow{3}{*}{$\left(\begin{array}{c}T_{c} \\
\left({ }^{\circ} \mathrm{C}\right)\end{array}\right.$} & \multirow{3}{*}{$\begin{array}{l}\rho \\
(\mu \Omega- \\
\mathrm{cm}, \\
20^{\circ} \mathrm{C}\end{array}$} & \multirow{3}{*}{$\begin{array}{c}\mathrm{Hv} \\
\text { (Vickers } \\
\text { hardness) }\end{array}$} \\
\hline & $\mathrm{Fe}$ & $\mathrm{Ta}$ & Temp. & Time & & & & & & & & & & & & \\
\hline & \multicolumn{2}{|c|}{ Rest Ni } & & & & & & & \multicolumn{3}{|c|}{$B_{m}=5 \mathrm{kG}$} & \multicolumn{2}{|c|}{$H=1 \mathrm{kOe}$} & & & \\
\hline 16 & 14.53 & 10.67 & 1150 & 11 & 800 & 13 & 152 & 279 & 15.1 & 4.1 & 9.2 & 8.2 & 1.1 & - & 51.9 & 177 \\
\hline 23 & 13.40 & 11.60 & 1250 & 2 & 1400 & 13 & 153 & 315 & 12.9 & 4.5 & 8.7 & 7.7 & 0.9 & 432 & 55.1 & 190 \\
\hline 29 & 13.16 & 13.85 & 1250 & 3 & 1400 & 35 & 402 & 263 & 11.0 & 3.6 & 7.3 & - & - & - & - & 198 \\
\hline 31 & 12.80 & 13.80 & 1150 & 6 & 1400 & 45 & 502 & 265 & 10.9 & 3.6 & 6.8 & 7.4 & 0.7 & 395 & 62.9 & 197 \\
\hline 31 & 12.80 & 13.80 & 1250 & 2.5 & 600 & 26 & 33 & 451 & 7.5 & 4.4 & 5.0 & 7.4 & 0.7 & - & 63.7 & 202 \\
\hline 34 & 12.05 & 14.95 & 1250 & 4 & 800 & 60 & 864 & 486 & 6.1 & 3.5 & 3.7 & 7.4 & 0.5 & 374 & 64.2 & 197 \\
\hline 34 & 12.05 & 14.95 & 1250 & 5 & 800 & 54 & 975 & 594 & 5.1 & 3.6 & 3.3 & 7.4 & 0.5 & - & 64.2 & 204 \\
\hline 35 & 11.59 & 14.66 & 1300 & 1 & 1400 & 48 & 531 & 141 & 10.6 & 1.6 & 7.0 & - & - & - & - & - \\
\hline 39 & 11.88 & 15.90 & 1250 & 3 & 1400 & 34 & 422 & 242 & 9.8 & 3.2 & 6.7 & 6.8 & 0.7 & - & 70.7 & 209 \\
\hline 40 & 11.60 & 15.40 & 1250 & 0.5 & 800 & 75 & 1024 & 468 & 5.3 & 3.1 & 3 & 6.6 & 0.5 & 380 & 70.1 & 216 \\
\hline 40 & 11.60 & 15.40 & 1250 & 3 & 800 & 72 & 1166 & 650 & 3.9 & 3.3 & 2.9 & 6.6 & 0.4 & - & 70.1 & 211 \\
\hline 47 & 11.10 & 16.50 & 1150 & 3 & 1400 & 27 & 332 & 227 & 10.0 & 3.6 & 8.5 & 6.4 & 0.4 & 340 & 75.1 & 210 \\
\hline 48 & 10.57 & 16.61 & 1250 & 1.5 & 400 & 54 & 591 & 124 & 8.4 & 1.5 & 6.8 & - & - & - & - & 226 \\
\hline
\end{tabular}

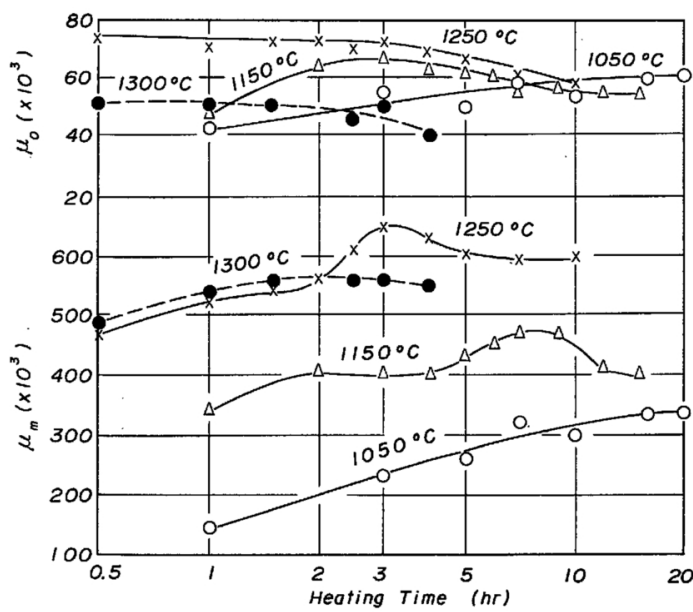

Fig. 4 Effect of the heating temperature and time on initial permeability $\mu_{0}$ and maximum permeability $\mu_{m}$ for alloy No. $40(73.00 \% \mathrm{Ni}, 11.60 \% \mathrm{Fe}, 15.40 \%$ Ta) cooled at the rate of $800^{\circ} \mathrm{C} / \mathrm{hr}$ after heating at the cited temperatures.

under a load of $500 \mathrm{~g}$. As can be seen from the table, $\mathrm{Ni}-\mathrm{Fe}$ alloys with added $\mathrm{Ta}$ have remarkably high permeabilities, with very low values of $W_{h}$ and $H_{c}$. Figure 4 shows the dependence of $\mu_{o}$ and $\mu_{m}$ on heating temperature and time for alloy No. 40 which exhibits the highest values of $\mu_{o}$ and $\mu_{m}$, when the alloy was heated at several temperatures under a hydrogen atmosphere and cooled at the rate of $800^{\circ} \mathrm{C} / \mathrm{hr}$. At a relatively low heating tempera-

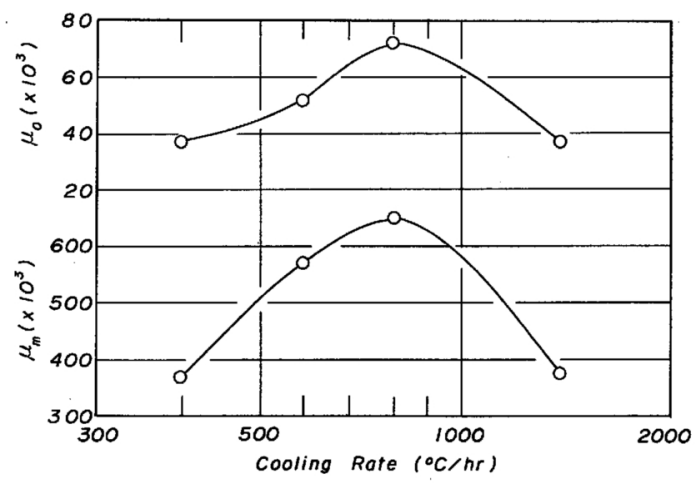

Fig. 5 Variations in initial permeability $\mu_{0}$ and maximum permeability $\mu_{m}$ with cooling rate for alloy No. $40(73.00 \% \mathrm{Ni}, 11.60 \% \mathrm{Fe}, 15.40 \%$ Ta) heated at $1250^{\circ} \mathrm{C}$ for $3 \mathrm{hr}$.

ture, $\mu_{o}$ and $\mu_{m}$ have a maximum, respectively, and the heating time at which the maximum is revealed becomes shorter with a rise in heating temperature. The drop in permeability is produced at a heating temperature of $1300^{\circ} \mathrm{C}$, the cause of which, however, remains unknown.

Figure 5 shows the dependence of $\mu_{o}$ and $\mu_{m}$ on cooling rate for alloy No. 40 when heated at $1250^{\circ} \mathrm{C}$ for $3 \mathrm{hr}$ and cooled from a temperature above its order-disorder transformation point. Both $\mu_{o}$ and $\mu_{m}$ have a maximum depending on cooling rate, and the appearance of this maximum may be attributed to its cooling rate that 
causes the alloy to have an atomic arrangement in which magnetization can most easily take place. The optimum cooling rate to reveal the maximum becomes smaller as the Ta concentration is increased. These tendencies bear a marked resemblance to the effects of additions of $\mathrm{Cr}, \mathrm{Mo}, \mathrm{Cu}$ and $\mathrm{Nb}$ to $\mathrm{Ni}-\mathrm{Fe}$ alloys ${ }^{(2)} \sim(4)$.

Figure 6 shows the dependence of $4 \pi I, T_{c}, \rho$ and $\mathrm{Hv}$ on $\mathrm{Ta}$ concentration for eacn of alloys on the dotted line $\mathrm{ab}$ in Fig. 2 when subjected to the heat treatment by which the highest value of $\mu_{m}$ was obtained. It is obvious from the figure that $4 \pi I$ and $T_{c}$ decrease monotonically and $\rho$ and $\mathrm{Hv}$ increase lineally as the Ta concentration is increased. Figure 7 illustrates the hysteresis loop of alloy No. 40 by heating at $1250^{\circ} \mathrm{C}$ for $3 \mathrm{hr}$ and subsequent cooling at the rate of $800^{\circ} \mathrm{C} / \mathrm{hr}$, in which $H_{c}$ and $W_{h}$ are very low at $2.9 \mathrm{mOe}$ and $3.9 \mathrm{erg} / \mathrm{cm}^{3} /$ cycle, respectively.

The origins of the high permeability of $\mathrm{Ni}-\mathrm{Fe}-$ Ta alloys may be ascribed mainly to homogenization of the alloys, removal of impurities such as carbon, nitrogen and oxygen and grain growth by high-temperature heat treatment under hydrogen atmosphere ${ }^{(5)(6)}$, and also to the low values in magnetostriction constant (cf. Table 1) and crystal magnetic anisotropy constant due to the atomic arrangement in the ordered state ${ }^{(7)}$.

The hardness of $\mathrm{Ni}-\mathrm{Fe}-\mathrm{Ta}$ alloys was found to be fairly high. For example, the hardness of alloy No. 40 having the highest initial permeability in the alloy system is 216 , which is remarkably high as compared with the hardness range of about 120 for conventional Permalloy and Mo-Permalloy. Since Ni-Fe-Ta alloys have not only high permeability but also exhibit a high value of hardness, the generic name Hardperm (diminutive of hard permeable alloy) has been given to these alloys.

\section{Conclusions}

Thirty-three alloys having the range of composition from 70.03 to $77.41 \% \mathrm{Ni}, 9.50$ to $15.96 \% \mathrm{Fe}$ and 9.57 to $17.80 \% \mathrm{Ta}$ were melted in vacuum, forged and then rolled, from which ring-shaped plates were made by stamping. The plates were heated in the range 1050 to

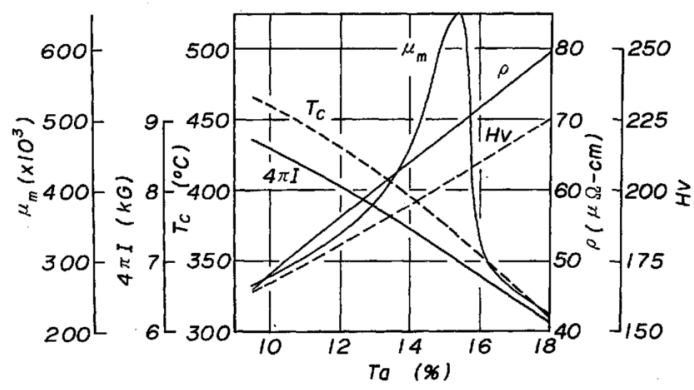

Fig. 6 Highest maximum permeability $\mu_{m}$ for each alloy on the dotted line in Fig. 2, and intrinsic magnetic induction $4 \pi I$, magnetic transformation point $T_{c}$, electrical resistivity $\rho$ and Vickers hardness $\mathrm{Hv}$ when subjected to the heat-treatment to develop the highest $\mu_{m}$.

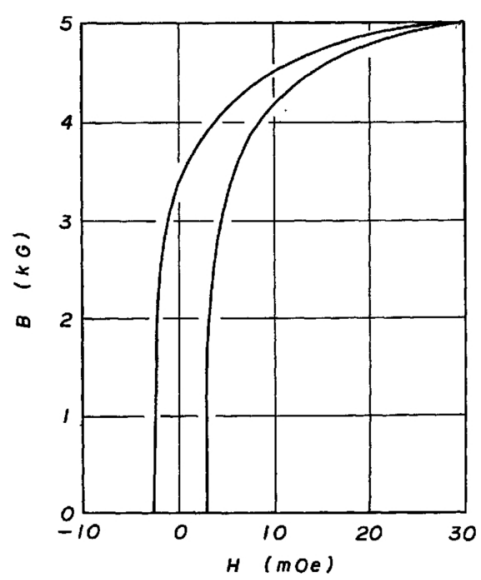

Fig. 7 Hysteresis loop of alloy No. $40(73.00 \% \mathrm{Ni}$, $11.60 \% \mathrm{Fe}, 15.40 \% \mathrm{Ta})$ cooled at the rate of $800^{\circ} \mathrm{C} /$ $\mathrm{hr}$ after heating at $1250^{\circ} \mathrm{C}$ for $3 \mathrm{hr}$.

$1350^{\circ} \mathrm{C}$ under a hydrogen atmosphere with a dew point of $-70^{\circ} \mathrm{C}$ for various lengths of time. Finally cooling was done at various rates from a temperature above their order-disorder transformation points. The following conclusions are drawn from measurements of magnetic properties, electrical resistivity and hardness for the alloy specimens:

(1) Considerable improvements of the properties of $\mathrm{Ni}-\mathrm{Fe}-\mathrm{Ta}$ alloys have been effected by heating in hydrogen atmosphere at high temperature. With the increased Ta concentration, the highest values of initial permeability and maximum permeability in each alloy increase until a maximum is reached; then the values are slowly reduced. The highest value of 
75000 in initial permeability and of 650000 in maximum permeability has been obtained with alloy No. 40 of $73.00 \% \mathrm{Ni}, 11.60 \% \mathrm{Fe}$ and $15.40 \% \mathrm{Ta}$ subjected to cooling at the rate of $800^{\circ} \mathrm{C} / \mathrm{hr}$ after heating at $1250^{\circ} \mathrm{C}$ for $30 \mathrm{~min}$ and $3 \mathrm{hr}$, respectively.

(2) The hysteresis loss and coercive force for a maximum magnetic induction are generally very small; their values of alloy No. 40 which underwent a heat treatment to reveal the highest value of maximum permeability are $3.9 \mathrm{erg} / \mathrm{cm}^{3} /$ cycle and $2.9 \mathrm{mOe}$, respectively. The electrical resistivity and the Vickers hardness of the alloy are as fairly high as 70.1 $\mu \Omega-\mathrm{cm}$ and 211 , respectively.

(3) The origins of the high permeability of $\mathrm{Ni}-\mathrm{Fe}-\mathrm{Ta}$ alloys may be attributed chiefly to homogenization, removal of impurities and grain growth by high-temperature heat treatment in hydrogen atmosphere and also to the low magnetostriction constant due to an atomic arrangement in the ordered state.

(4) Since Ni-Fe-Ta alloys are considerably higher in hardness than conventional Permalloy and Mo-Permalloy in addition to their high permeability, the generic name Hardperm has been given to these alloys.

\section{REFERENCES}

(1) H. Masumoto, Y. Murakami and M. Hinai : J. Japan Inst. Metals, 36 (1972), 63; Trans. JIM, 14 (1973), 242.

(2) G. W. Elmen: Elec. Eng., 54 (1935), 1292.

(3) D. J. Snee: J. Appl. Phys., 38 (1967), 1172.

(4) H. Masumoto, Y. Murakami and M. Hinai : J. Japan Inst. Metals, 35 (1971), 985; 38 (1974), 238; Trans. JIM, 13 (1972), 182; 15 (1974), 261.

(5) P. P. Cioffi: Phys. Rev., 39 (1932), 363.

(6) R. E. S. Walters: Acta Met., 3 (1955), 293.

(7) I. M. Puzei: Izv. Akad. Nauk USSR, Ser, Fiz. 16 (1952), 549. 